This item was submitted to Loughborough's Research Repository by the author.

Items in Figshare are protected by copyright, with all rights reserved, unless otherwise indicated.

\title{
In-situ temperature monitoring directly from cathode surface of an operating solid oxide fuel cell
}

PLEASE CITE THE PUBLISHED VERSION

https://doi.org/10.1016/j.apenergy.2020.116013

\section{PUBLISHER}

Elsevier Ltd

VERSION

AM (Accepted Manuscript)

\section{PUBLISHER STATEMENT}

This paper was accepted for publication in the journal Applied Energy and the definitive published version is available at https://doi.org/10.1016/j.apenergy.2020.116013.

\section{LICENCE}

CC BY-NC-ND 4.0

\section{REPOSITORY RECORD}

Guk, Erdogan, Manoj Ranaweera, Vijay Venkatesan, Jung-Sik Kim, and WooChul Jung. 2020. "In-situ Temperature Monitoring Directly from Cathode Surface of an Operating Solid Oxide Fuel Cell". Loughborough University. https://hdl.handle.net/2134/13160033.v1. 


\title{
IN-SITU TEMPERATURE MONITORING DIRECTLY FROM CATHODE SURFACE OF AN OPERATING SOLID OXIDE FUEL CELL
}

\author{
Erdogan Guk ${ }^{1,2}$, Manoj Ranaweera ${ }^{3}$, Vijay Venkatesan ${ }^{1}$, Jung-Sik Kim¹ ${ }^{*}$, WooChul Jung ${ }^{4}$ \\ ${ }^{1}$ Aeronautical \& Automotive Engineering Department, Loughborough University, LE11 3TU, \\ United Kingdom \\ ${ }^{2}$ Bozok Üniversitesi, Mühendislik-Mimarlık Fakültesi, Erdoğan AKDAĞ Kampüsü, Atatürk Yolu 7. \\ $\mathrm{km}$, Yozgat, Turkey \\ ${ }^{3}$ Department of Mechanical Engineering, University of Moratuwa, Sri Lanka \\ ${ }^{4}$ Department of Materials Science and Engineering, Korea Advanced Institute of Science \\ and Technology (KAIST), Daejeon 34141, Republic of Korea
}

\begin{abstract}
The electrode temperature distribution of a solid oxide fuel cell is an important parameter to consider for gaining better insight into the cell performance and its temperature-related degradations. The present efforts of measuring gas channel temperatures do not accurately reveal the cell surface temperature distribution. Therefore, the authors propose a cell-integrated multi-junction thermocouple array to measure the electrode temperature distribution from a working solid oxide fuel cell. In this work, the authors deposited a thin film/wire multi-channel thermal array on the cathode of a commercially-sourced solid oxide fuel cell. The temperature of the cell was measured under varying fuel compositions of hydrogen and nitrogen. The multichannel array showed excellent temperature correlation with the fuel flow rate and with the cell's performance whilst commercial thermocouples showed a very dull response $\left(\sim 10-20{ }^{\circ} \mathrm{C}\right.$ discrepancy between thermocouples and the multi-channel array). Furthermore, cell temperature measurements via the multi-channel array enabled detecting potential fuel crossover. This diagnostic approach is applied to a working solid oxide fuel cell, yielding insights into key degradation modes including gas-leakage induced temperature instability, its relation to the theoretical open circuit voltage and current output, and propagation of structural degradation. It is envisaged that the use of the multi-thermocouple array techniques could lead

Selection and peer-review under responsibility of the scientific committee of the 11th Int. Conf. on Applied Energy (ICAE2019).

Copyright (C) 2019 ICAE
\end{abstract}


to significant improvements in the design of electrochemical energy devices, like fuel cells and batteries and their safety features, and other hard-to-reach devices such as inside an internal combustion engine or turbine blades.

Keywords: solid oxide fuel cells, cathode temperature of SOFC, thin-film thermocouples, multithermocouple array, fuel flowrate-OCV relationship

\section{INTRODUCTION}

It is obvious that there is a significant increase in energy demand with the continuous development in technology. Thus, it is critically important to increase the nature friendly technologies with increased efficiency to minimize the negative impact of fossil fuels when they are used as energy sources[1], [2]. Solid Oxide Fuel Cell (SOFC) as an energy conversion device is considered as promising technology for electricity generation due to its high conversion efficiency (50\% to $75 \%$ in combined cycles) and important environmental benefits [3], [4], [5], [6], [7], [8]. This mainly comes from the direct conversion of chemical fuels to electrical energy, fuel flexibility and high operation temperature of SOFCs. SOFCs have the possibility of using various fuels such as hydrogen, methane and carbon monoxide without requiring expensive catalyst material due to high operating temperatures. Furthermore, the fuel flexibility allows for the opportunity to use an SOFC system in other applications including mobile applications, stand alone, remote and automotive auxiliary units [7], [9], [10]. However, premature degradation of cells and stacks is a significant challenge to ensure the longevity of SOFCs and to make them a commercially viable technology to produce cleaner electricity [11], [12], [13]. Among various factors affecting the premature degradation of SOFCs, thermal cycling at high temperatures (usually in a range from $600{ }^{\circ} \mathrm{C}$ to $900^{\circ} \mathrm{C}$ ) and uneven temperature distribution are two dominant factors [14], [15]. Severe mechanical failures such as formation and propagation of cracks and failures in gas sealing are typical temperature-driven failures at cell level, while failures of interconnect sealing is one of the stack level problems aggravated by uneven temperature distribution [4], [5]. Despite the aforementioned problems, some uniquely meritorious characteristics of SOFC such as fuel flexibility, high energy conversion efficiency, and liberation 
from the expensive catalyst at the anode, are inherited from the high operating temperature. Therefore, acquiring a comprehensive knowledge of the cell and stack level temperature distribution is vital to mitigate premature degradation while preserving the meritorious characteristics of SOFC. Further, in-situ temperature sensing enables to investigate the detrimental evolutions of temperature profiles induced due to changes in the operating conditions such as current, flow rate, etc. thus, facilitating real-time health monitoring [3], [6], [11].

There are different techniques, such as IR thermometry [16], and Raman Spectroscopy [17], employed to estimate or measure the temperature distribution of an operating SOFC. Infrared thermometer (IR) was used for SOFC surface in-situ temperature and deformation measurement at $800{ }^{\circ} \mathrm{C}$ [18]. Nevertheless, it is noted that the system needs more improvement in terms of its instrumentation and the obtained spatial resolution which is related to the proximity of the measurement location. Due to the requirement of the SOFC's gas-tight closed system, it is difficult for IR to access the active zone for better detection [7], [4]. Similar accessibility problems arise for Raman Spectroscopy with the addition of its inadequate performance at high temperature [4]. As it is important to obtain high spatial and temporal characteristics to reach a more realistic measurement, which is related to the time dependent response from the sensing thermocouple thermometry appears to be the most widely used technology [5], [19]. Further, compared to the above techniques, thermocouples require relatively low stack modifications to accommodate them in an SOFC system. Thus, they can provide a more realistic temperature measurement, which may be strictly comparable to the operating temperature of a cell/ stack under its normal operation. However, a principal drawback of thermocouples in SOFC temperature sensing is its inability to measure the electrode temperature with sufficiently high spatial resolution. To overcome this problem while preserving the advantageous characteristics of thermocouples, especially of thin film thermocouples, the authors proposed cell integrated thin film multi-junction arrays [8].

This paper demonstrates and discusses the application of a multi-channel thermal array (MCTA) to measure the temperature distribution over the cathode of an SOFC under varying fuel compositions. Furthermore, a correlation between cell temperature and its open circuit voltage 
(OCV) is discussed, alongside an OCV-fuel composition correlation, and a detection of fuel crossover to cathode. The presented work tracks the progression of internal temperature distribution leading up to and during electrochemical activities. This new approach builds on the previous research performed by the authors' group [1], [2] allows us to observe the effects of gas leakage, venting and elevated temperature on the surface of internal layers of commercial SOFCs and to evaluate the influence of SOFC operational engineering on cells safety and performance. Also, another feature of this approach is that it does not require specially arranged or cuttingedge/bespoke equipment, but the resourceful redeployment of the well-exploited Seebeck effect for such observations. Finally, the temperature data

\section{METHOD AND MATERIALS}

From among different high-temperature thermocouple materials, K-type materials (alumel Ni:Al:Mn:Si $95: 2: 2: 1$ by wt. and chromel - Ni:Cr 90:10 by wt.) were chosen for the thermoelements as they have sufficiently broad range to cover the entire operating temperature range of a typical SOFC (from room temperature to about $800{ }^{\circ} \mathrm{C}$ ). The initial experimentation was focused on proving the functionality of MCTA on a fuel cell in OCV conditions, and observing temperature-OCV correlations, along with other influences (e.g. fuel composition and flow rate). For the subsequent investigation on practical cell operating conditions (drawing current and producing power), a thin film MCTA having four sensing points (hence requiring only 5 thermoelements), and a thin wire MCTA having 9 nine sensing points (6 thermoelements) were fabricated. In both instances, the distance between the sensor sensing points kept as $10 \mathrm{~mm}$ which was calculated as the minimum safe distance in term of thermal interference between junctions. Thus, four sensing points with thin film array and nine sensing points with grid wired sensor architecture are found to be a convenient architecture for the proposed SOFC cell with $50 \mathrm{~mm} \times 50 \mathrm{~mm}$ dimensions, which is elaborated in the subsequent section.

\subsection{Sensor Fabrication and Integration}

An MCTA having four sensing points, hence five thermoelements only, was sputter deposited on the cathode of a $50 \mathrm{~mm} \times 50 \mathrm{~mm}$ commercial SOFC (NextCell-5) using Quorum QT 150TS 

$\mathrm{nm} / \mathrm{min}$ were employed to obtain a film thickness of approximately $500 \mathrm{~nm}$. The alumel thermoelements were deposited prior to the chromel thermoelement. The pattern was obtained using two stainless steel masks of thickness $0.075 \mathrm{~mm}$ each: one for alumel thermoelements and the other for chromel thermoelement. To prevent stainless steel masks from being lifted due to the magnetic field inside the sputter chamber, the masks were forced onto the cathode by using two thin wood strips (spatula). The width of each thermoelement is approximately $0.2 \mathrm{~mm}$. Each open end of a thermoelement has a $3 \mathrm{~mm} \times$ $3 \mathrm{~mm}$ connection pad to facilitate external wire connection. External wires $(\varnothing 0.25 \mathrm{~mm})$ of the same material as the thermoelements were connected to thin film thermoelements at the connection pads. The edge of all the wires, which were in touch with the connection pads, was gold plated using sputter deposition to prevent possible oxidation of the connection interface at high temperature. Approximately half the perimeter of the wires was expected to have a gold layer as they were kept horizontally during the deposition. Silver paste (Aremco-bond 597) was applied to the connection points, as shown in Fig. 1(a), to increase the electrical connectivity between the film and the wire. The electrolyte-supported test cell used for the experiment is shown in Fig. 1(b) having its cathode facing up. The wires were routed through ceramic beads (RS Components UK) for thermal and electrical insulation. Due to greater consistency of fabrication during sputtering and effective external wire connection mechanisms, a straight line is selected instead of alternative arrangements, such as circular, which requires circular ceramic strips to hold the wires. However, for the subsequent studies, the shape could be improved for more sensing points with minimum coverage of the cell active surface, particularly when the cell would be in a current-drawing situation or loading condition.

The wire-connected cell was placed in a furnace for 2 hours at $90^{\circ} \mathrm{C}$ to allow silver to solidify. Since silver did not provide sufficient mechanical strength to hold the wires in place during handling, two thin strips of alumina sheets were glued to the cell using an alumina adhesive (Ceramobond 552, Aremco). The thin films and the connection pads were intentionally made free of alumina to eliminate any influence from alumina on the performance of the MCTA 
with thin film form. Curing alumina for 2 hours in a furnace at $100{ }^{\circ} \mathrm{C}$ made a strong alumina bond which firmly holds the wires in place while giving enough freedom to handle the wires. This cell-sensor setup was only evaluated when the cell was under open circuit conditions to monitor OCV-cell surface temperature relationships. Thus, the impact of the applied materials onto cathode surface was considered as negligible due to not drawing current from the system.
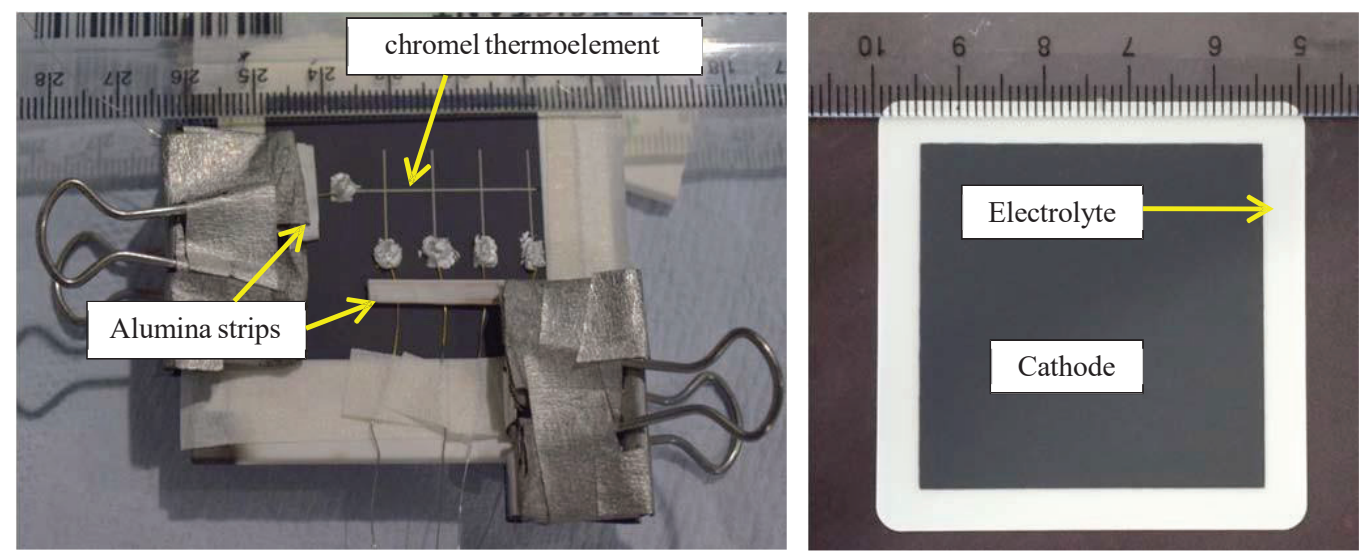

Fig. 1 (a, left) External wire connected cell, (b, right) the SOFC test cell (NextCell-5) with the cathode facing up before connecting wires

The two electrodes are $50 \mu \mathrm{m}$ thick each, and the electrolyte is between $0.13-0.17 \mathrm{~mm}$ in thickness. The electrolyte supported cell (NextCell-5) is sourced commercially (Fuel Cell Materials, US), where the anode is made of $\mathrm{NiO} / \mathrm{GDC}-\mathrm{NiO} / \mathrm{YSZ}$ and the cathode is made of LSM-DC. The electrolyte is a Scandia-based proprietary formulation known as Hionic ${ }^{\mathrm{TM}}$, where the exact composition is not known. The thin film MCTA-integrated cell was fixed to the SOFC test rig as shown in Fig. 2-top-left. $S 1$ to $S 4$ are the four sensing points of the thin film MCTA. The cell was placed between two gaskets (Thermiculite ${ }^{\circledR} 866$, Flexitallic UK) to prevent any gas leakages through the interface between the cell and the ceramic cell holder. Current collector meshes made of nickel and platinum were attached to the anode and to the cathode, respectively, using silver paste. 
For the investigations concerning practical cell operation (under load), an MCTA with 9 sensing points (with only 6 external wires) was fabricated. The wire-based sensor utilised spot welding to create junctions. Two adjacent commercial thermocouples (K-type) were also fixed onto the cathode for comparison purposes. The thermocouples are conformance-certified from TC Ltd. Calibration Laboratories (United Kingdom). The tip of one thermocouple was at S1 approximately $2 \mathrm{~mm}$ above the cathode while the other's tip was between S1 and S2 sensing points having its tip approximately $5 \mathrm{~mm}$ above the cathode. The surface of the used thermoelements of wired sensor was oxidized at high temperature and electrically nonconductive which avoids electrical interference with cell surface. For the thin wire based SOFC loading experiments, schematics of the location of two commercial thermocouples and nine sensing points are shown in Fig. 2-bottom-right. The fuel supply pipe was approximately underneath $S 2$ sensing point and about $2 \mathrm{~cm}$ below the anode. Oxygen for cathodic reactions was taken from the ambient air inside the furnace. No external air supply was utilized in order to prevent excessive cooling as gas pre-heating was not employed.

Since chromel contains chromium, it may not be an ideal thermocouple material for the cathode due to the potential danger of chromium poisoning. However, the experiment did not last longer than 2-3 hours. This duration can be considered as too short for chromium poisoning to take place. Therefore, this study did not consider the detrimental effects of chromium on the cathode. In fact, thermocouples used for SOFC temperature sensing in the literature are also mostly K-type thermocouples.

Although the accuracy and sensitivity of temperature measurements from thin-film thermocouples are influenced by the film thickness [20], [21], the performance of K-type thermocouples is independent of the film thickness when the thickness is greater than about 140 $\mathrm{nm}$ [22]. Since the fabricated films were much thicker than this threshold value, the performance of the thin film MCTA can be considered to be independent of the film thickness. Furthermore, the junction sizes were also much larger than the threshold value of $9 \mu \mathrm{m}^{2}$ [23] to get any influence from its size to the performance. Thus, the thin film multi-junction thermocouples can be considered free from any dimensional influence on their performance 
Fig. 2 (Top-left) The cell fixed to the cathode thin film one, (Top-right) grid wire formed MCTA, (Middle) Wired sensor-cell setup, (Bottom-left) schematic of positioning of the grid and the current collector on the cathode (Bottom-right) relative locations of commercial thermocouples and the dimensions of the grid.
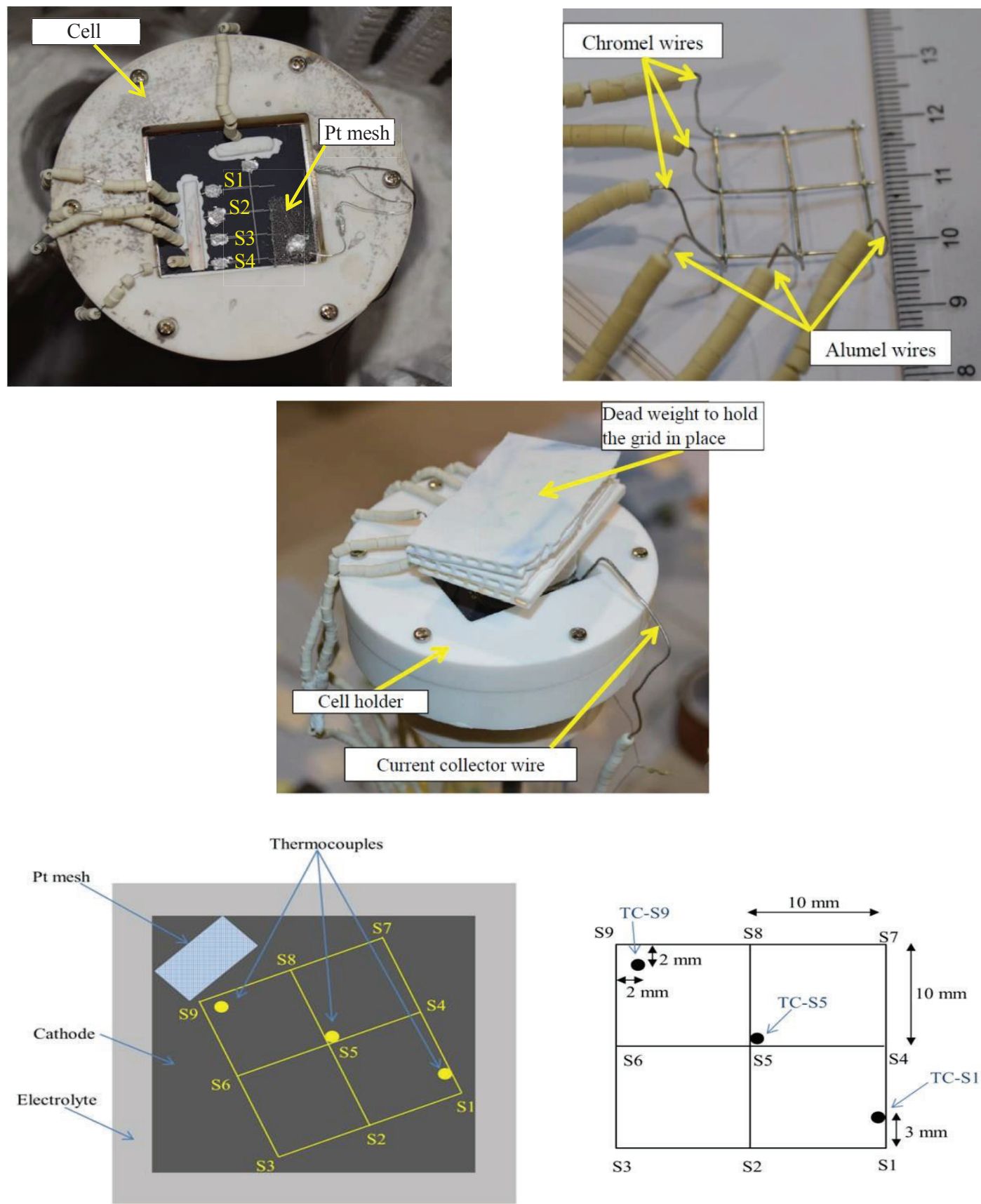


\subsection{SOFC operation}

The furnace of SOFC test rig was heated at $500{ }^{\circ} \mathrm{C}$ per hour up to $750{ }^{\circ} \mathrm{C}$. Nitrogen was supplied to the anode chamber at a rate of $300 \mathrm{ml} / \mathrm{min}$ since the beginning of the heating process to expel air inside the anode chamber to facilitate anode reduction. Hydrogen was introduced at a volumetric rate of $15 \mathrm{ml} / \mathrm{min}$ from approximately $650{ }^{\circ} \mathrm{C}$ to start the reduction process and continuously supplied for about $30 \mathrm{~min}$ (at $750{ }^{\circ} \mathrm{C}$ cell temperature) for the anode reduction to complete. The test rig consists of a bottom tube which has a central gas supplying pipe for gas inlet and hole at the bottom for unused or excess gas outlet. The bottom tube, which faces with the cell holder anode side, is isolated from the air and gas tight. The gas pipe was located to center of the tube thus the provided gas comes to center of the anode and distributed to other parts of it. Cathode side on the other hand is open air.

After the reduction process, a mixture of hydrogen and nitrogen, having the total volumetric flow rate of $250 \mathrm{ml} / \mathrm{min}$, was supplied at varying volumetric compositions as listed in Table 1. The hydrogen flow rate was controlled via Bronkhorst ${ }^{\mathrm{TM}}$ Flow EL Mass Flow Controllers, using FlowView software while the nitrogen flow was manually controlled. Because of the manual control of nitrogen, it took nearly 30 seconds to settle the total flow rate at $250 \mathrm{ml} / \mathrm{min}$ at each flow changes. The flow rates were cycled to assess the repeatability of measurements to enhance the reliability. The duration of each flow rate was set to approximately 10 min to enable the cell to stabilise its temperature and OCV. The furnace temperature was maintained at $750{ }^{\circ} \mathrm{C}$ with an accuracy of $\pm 1{ }^{\circ} \mathrm{C}$. After experiment, the cell was brought back to room temperature under natural cooling. Nitrogen was continuously supplied at a constant rate of $250 \mathrm{ml} / \mathrm{min}$ throughout the cell cooling to prevent anode re-oxidation. 
Table 1 Volumetric flow rates

\begin{tabular}{|c|c|c|}
\hline Flow Region & Flow Rate $(\mathbf{m l} / \mathbf{m i n}) \mathbf{H}_{\mathbf{2}} / \mathbf{N}_{\mathbf{2}}$ & Time (min) Approx. \\
\hline A & $100 / 150$ & 10 \\
\hline B & $150 / 100$ & 10 \\
\hline C & $200 / 50$ & 10 \\
\hline D & $250 / 0$ & 10 \\
\hline E & $200 / 50$ & 10 \\
\hline F & $150 / 100$ & 10 \\
\hline G & $100 / 150$ & 10 \\
\hline
\end{tabular}

\section{RESULTS AND DISCUSSIONS}

Fig. 3 shows the temperature measured by the thin film MCTA and the two commercial thermocouples under varying fuel compositions as published in authors previous work [24]. Regions marked by letters from $A$ to $G$ are the flow configurations given in Table 1. Temperatures measured by the two thermocouples (RS - Pro), which has faceplate accuracy of $+0.004 T$, recorded approximately $10^{\circ} \mathrm{C}$ lower temperature than the furnace's set temperature. Since the thermocouples were placed in the cathode chamber and the cathode was not provided with any air supply, no cooling effect can be expected on commercial thermocouples. Thus, it can be speculated that the observed temperature discrepancy is likely to be an actual temperature gradient present across the furnace. The presence of a temperature gradient between the two commercial thermocouples themselves (TC1 and TC2) supports this argument. Throughout the experiment, the cell temperatures measured by the thin film MCTA were noticeably lower than the temperature measured by the commercial thermocouples, which were not more than $5 \mathrm{~mm}$ from the cathode. This behaviour can be ascribed to a cooling effect that took place on the cell due to the impinging of non-preheated gas on the cell. This confirms that near-surface temperature sensing is not sufficient to sense cell temperature distribution of SOFCs. The sensing point S2, which was the closest sensing point to the gas supply (just right above it), shows the lowest cell temperature throughout the experiment. 54 , which was located furthest away from 
the gas inlet, showed the highest overall cell temperature throughout the experiment. Since 54 is furthest away from the gas inlet, the cooling effect near $\$ 4$ should be lower due low chilling resulted by uneven gas distribution at the anode surface. Since the cell was not active, no net heat generation could have taken place on the cell. Thus, the cooling effect predominantly determines the cell temperature distribution.

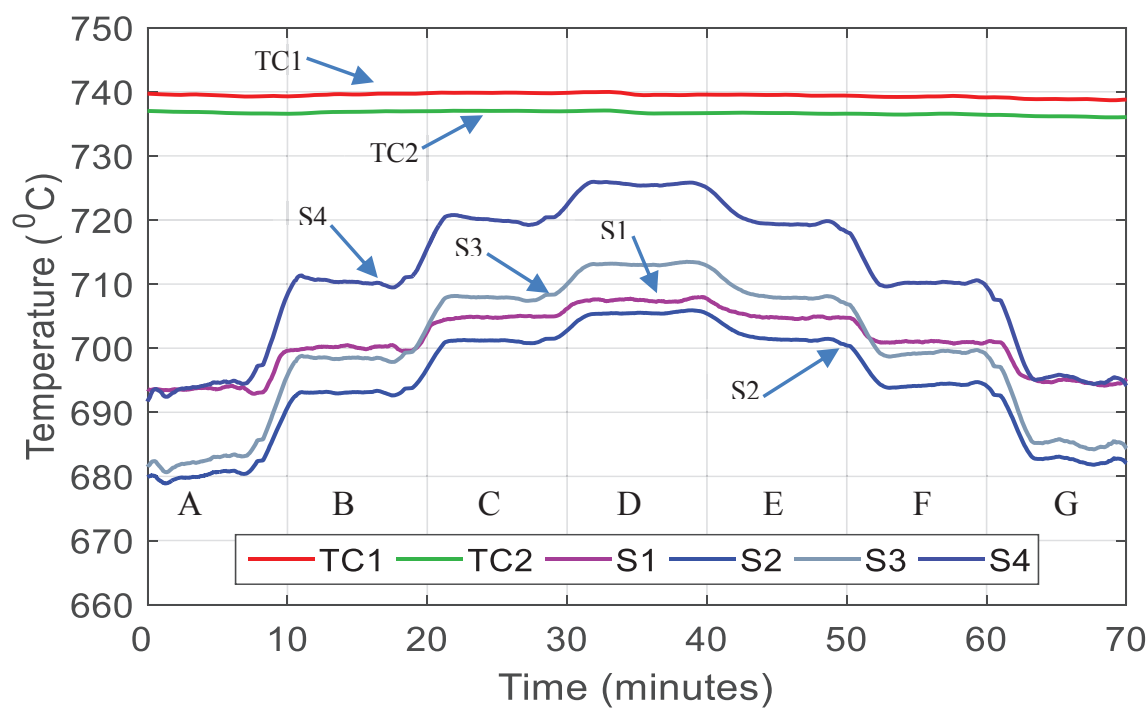

Fig. 3 Temperature response of the TCs and MCTA to varying flow rates [24]

Fig. 4 shows the temperature measurements made while the cell was cooling down to room temperature after the experiment. In contrast to previously observed temperature discrepancy between the MCTA and the commercial thermocouples where the MCTA's temperature was higher than the commercial thermocouples, this graph shows that the cell temperature remains higher than the cathode gas temperature. The slightly higher temperature of the cell during cooling can be understood concerning the thermal inertia of the cell as the authors previously described the same behaviour [8], [25]. The higher heat capacity of the cell due to its greater mass compared to air makes the cell to cool slower than the ambient air. Thus, its temperature can stay slightly higher than the nearby air during cooling. 
The overall cell temperature measured by the thin film MCTA showed a positive correlation with the hydrogen composition of the fuel mixture (see Fig. 3): the higher the hydrogen content in the fuel the higher the cell temperature. This correlation repeats as the volumetric composition was cycled confirming the verity of the observation. Since the cell was in an open circuit, the observed correlation is difficult to be ascribed to any chemical activity on the cell. Thus, the increase of the cell temperature with the increase of hydrogen content may likely to be linked with fuel crossover from the anode to cathode causing direct combustion of hydrogen on or near the cathode. Although the employed gaskets could prevent fuel from leaking to the cathode chamber through the interface between the cell and the cell-holder, the post experimental diagnosis of the test rig revealed the presence of a fuel leakage through a hole used to pass the anode's current collector wire into the anode chamber. Thus, when fuel leaks into the cathode chamber it could directly be oxidised thereby causing the temperature rise. Since more hydrogen is burnt at higher hydrogen compositions, more heat is liberated causing the temperature to rise more at higher hydrogen compositions. This adequately explains the positive correlation between the cell temperature and the volumetric composition of hydrogen; temperature increases during $A \rightarrow D$ while it decreases during $D \rightarrow A$. The changes in temperature are due to fuel leakage since a good correlation between the conventional TCs and the MCTA was obtained 


\begin{abstract}
Wei et al [27] also demonstrate a similar Nernst effect on the OCV with $\mathrm{H}_{2} \mathrm{~S}$ as the fuel. In contrast, in order to investigate the unrealistic proportional correlation between the cell temperature and the OCV, the OCV was recorded by varying the furnace temperature (from 700 ${ }^{\circ} \mathrm{C}$ to $800{ }^{\circ} \mathrm{C}$ with $25^{\circ} \mathrm{C}$ increments) while having set the volumetric compositions of hydrogen and nitrogen at $200 \mathrm{ml} / \mathrm{min}$ and $50 \mathrm{ml} / \mathrm{min}$, respectively. The average cell temperature,
\end{abstract}

when the sensor and TCs were tested with the absence of fuel as discussed in the previous studies by the author [26]. It is inferred from Fig. 4 that the TCs and MCTA readings are in good agreement where the difference arises only due to the inertia of the cell with negligible effect from the hydrogen oxidation at these temperatures.

The average OCV produced under different hydrogen compositions (total flow at constant 250 $\mathrm{ml} / \mathrm{min}$ with balance N2) was plotted against the volumetric hydrogen composition as shown in Fig. 5. The graph shows an increase of the OCV with the increase of hydrogen composition in the fuel. As the hydrogen composition increases during the corresponding period, the partial pressure of hydrogen increases thus, the OCV also increases (by $\simeq 0.023 \mathrm{~V}$ ), conforming to the well-known Nernst potential behaviour:

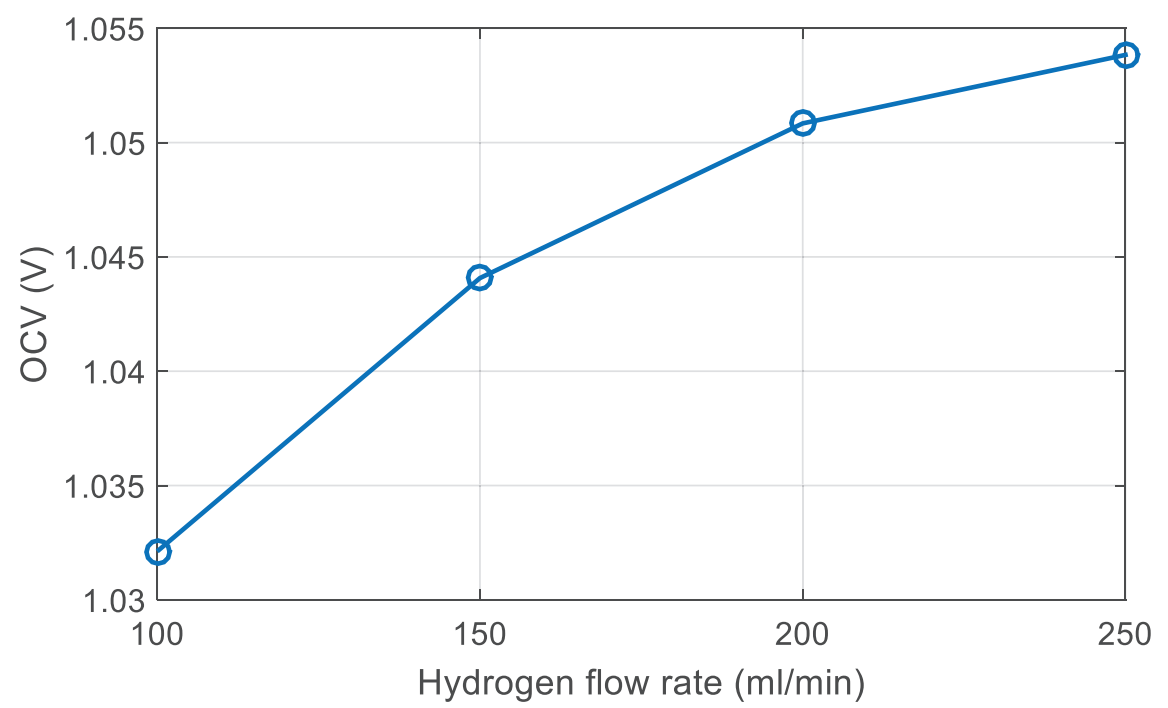

Fig. $5 \mathrm{OCV}$ vs hydrogen flow rate at $800{ }^{\circ} \mathrm{C}$ set temperature

$$
E_{\text {cell }}=E_{H 2}^{0}-\frac{R T}{2 F} \ln \left[\frac{p_{H 2 O}}{\left(p_{H 2}\right)\left(p_{O 2}\right)^{0.5}}\right]
$$


calculated by averaging the temperature measurements from the four sensing points of the MCTA and the temperatures from the two thermocouples, were plotted against time as shown in Fig. 6 (a). The regions marked by letters from $P$ to $T$ are the regions where the furnace temperature was set to remain constant at temperatures from $700{ }^{\circ} \mathrm{C}$ to $800{ }^{\circ} \mathrm{C}$ with $25{ }^{\circ} \mathrm{C}$ increments. The temperature discrepancy observed between the furnace set temperature and the thermocouple continued to appear in this test as well.

The slight overshoot of temperature at the beginning of each constant-temperature region is a result of the controlling characteristics of the furnace controller. Its PID controller tends to slightly overshoot prior to settling at the setpoint temperature. Taking 9 minutes intervals at each temperature region, where the cell temperature is reasonably stable, the average cell temperature per region was calculated. The OCV was plotted against the mean cell temperature as shown in Fig. 6 (b). This graph shows that the OCV decreases with the increase of the cell temperature agreeing with the Nernst temperature effect. Therefore, the previously observed positive correlation between the cell temperature and the OCV, where the OCV appeared to increase with the cell temperature, is a mere consequence of muddling the results of two mutually exclusive incidents: 1$)$ increasing the cell temperature $\left(28^{\circ} \mathrm{C}\right.$ on Average based on Fig 1
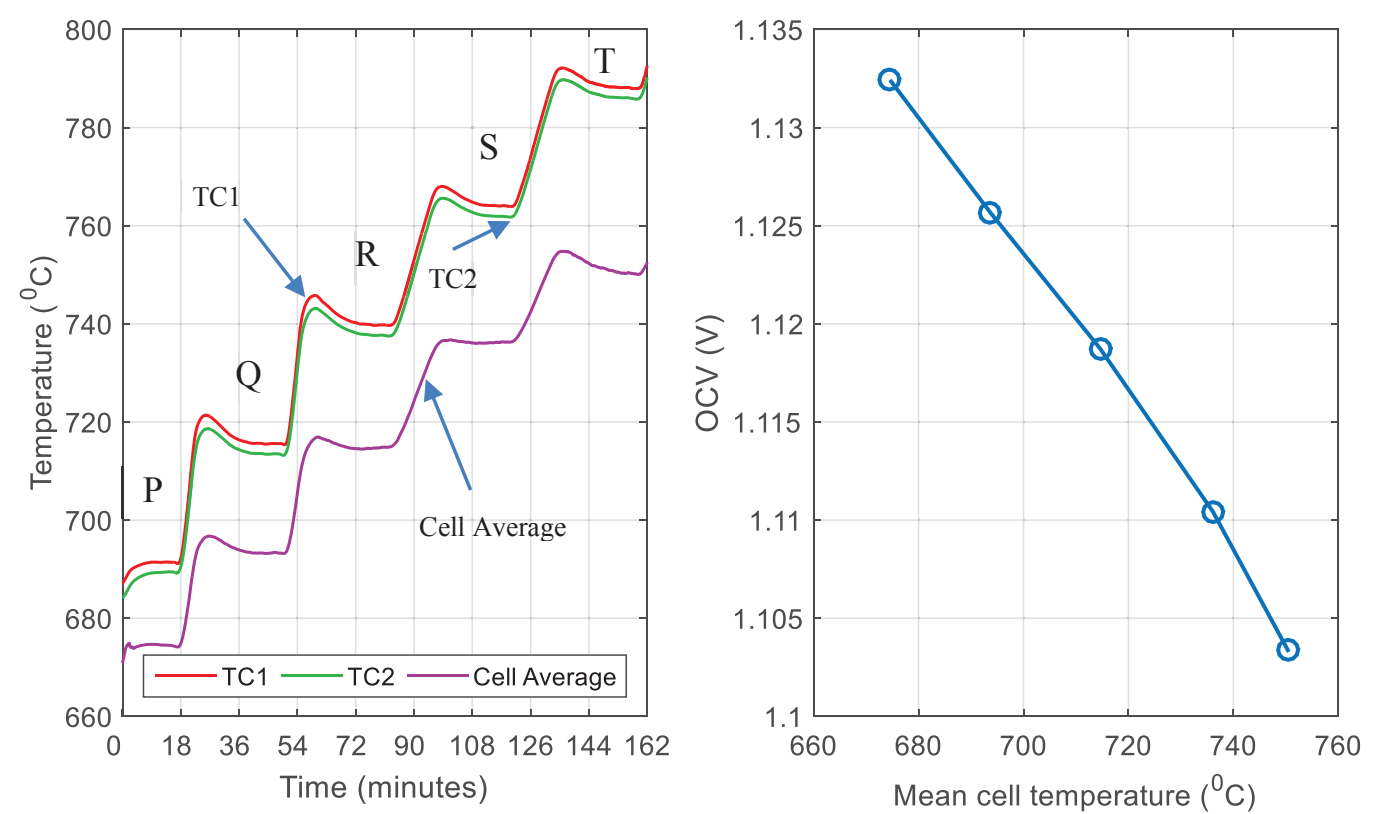

Fig. 6 Cell response to varying temperatures (a, left) The average cell temperature and the thermocouple temperature (b, right) the change of OCV with the increase of cell temperature 

varying fuel amount that took place in the cell, which the thin film MCTA could adequately detect. Therefore, it is demonstrated that the cell-integrated thin film MCTA could comprehensively detect the cell temperature distribution which subsequently led to the discovery of fuel leakage in the post experimental investigations. As the temperature distribution of SOFCs can now be read internally, this point should be clarified by addressing the operational temperature of SOFC. It should no longer be said that operating an SOFC system is at a fixed temperature (e.g. $750^{\circ} \mathrm{C}$ ), instead it can be expressed through a range e.g. at $750^{\circ} \mathrm{C} \pm 45^{\circ} \mathrm{C}$ as we now have a new tool to view these accurately in 2D space per cell, or even 3D space per stack. This amount of temperature variation may not be critical for this study; however, it is important for performance analysis of operational SOFCs due to direct relation between obtained voltage and cell temperature. Additionally, depending on the supplied fuel the temperature further increases, which can cause temperature-induced cracks on the cell components including electrolyte and electrodes [28].

\& 3 ) with the increase in volumetric composition of hydrogen ( 2.5 times) and 2 ) increasing the
OCV by $0.023 \mathrm{~V}$ with the increase in hydrogen composition ( 2.5 times). The measured OCVs were in reasonably close agreement with the manufacturer's specifications for the cell. It is anticipated that the increase of OCV would have been greater than what is recorded if the temperature did not increase. The overall $\mathrm{OCV}$ decrease in the $100^{\circ} \mathrm{C}$ increment is attributable to the greater effect of the Nernst potential-temperature correlation, as well as the lower seal pressure from relaxation of the fastening mechanism. This would allow gas leakage or crossover and would decrease the hydrogen partial pressure, incurring decrease of the OCV.

The maximum temperature gradient across the cell was measured to be approximately $20^{\circ} \mathrm{C}$ and, that took place across $S 2$ and $S 4$ sensing points which are only about $20 \mathrm{~mm}$ apart. Since the cell did not produce any power output (zero current draw in OCV), the electrochemical contribution from reaction kinetics should be obviated. Therefore, the cell temperature should entirely be caused by a combinational effect of cell chilling and fuel leakage. Importantly, the two commercial thermocouples have failed to follow the temperature changes around $10{ }^{\circ} \mathrm{C}$ with ectrodes [28]. 
The next investigation was carried out by employing a 9-point thin-wire based MCTA to focuses on assessing how a change in electric loading affects the cell's local temperature, shown in Fig. 7. All materials and testing environment were identical to above mentioned experiment except the form of sensor. This is to investigate the load-temperature relationship in addition to the temperature-voltage relationship. Hence, the inter-correlation parameter that describes the relationships between the cell's local temperature distribution and the current output could be identified.

The obtained polarization curve provides the electrical output characteristics of the operating SOFC cell as shown by Fig. 7. Cell voltage, $V$, as a function of drawn current, $m A$, is given with corresponding cathode surface temperature distribution from various sensing points of MCTA sensor relationships given in the figure. It can be noticed from approximately $72 \mathrm{~mA}$ onward that there is a slight downward exponential tendency which indicates a presence of concentration polarisation. In parallel to this, the cell temperature also shows a relatively steep increase. Concentration polarisation is an irreversibility, which causes entropy generation. With the growth of entropy, the portion of enthalpy being converted to heat increases and part of this heat contributes to rising the cell temperature. Considering the current output is only $72 \mathrm{~mA}$ at the given $\mathrm{H}_{2}$ flow rate $(100 \sim 150 \mathrm{ml} / \mathrm{min})$, the occurred concentration polarisation is likely due to mass transport limits via diffusive processes, rather than fuel starvation.

Thus, a relatively steep increase of cell temperature can be expected under concentration polarisation. The noticed concentration polarisation is likely occurred due to transport limits, cell temperature measurements may be used to identify the regions in a stack which do not get sufficient gas diffusion or supply. 
Table 2 lists the cell temperatures measured by the grid at its different sensing points and by the three commercial thermocouples when the cell was delivering no current (open circuit) and when it was producing approximately $71 \mathrm{~mA}$ current.

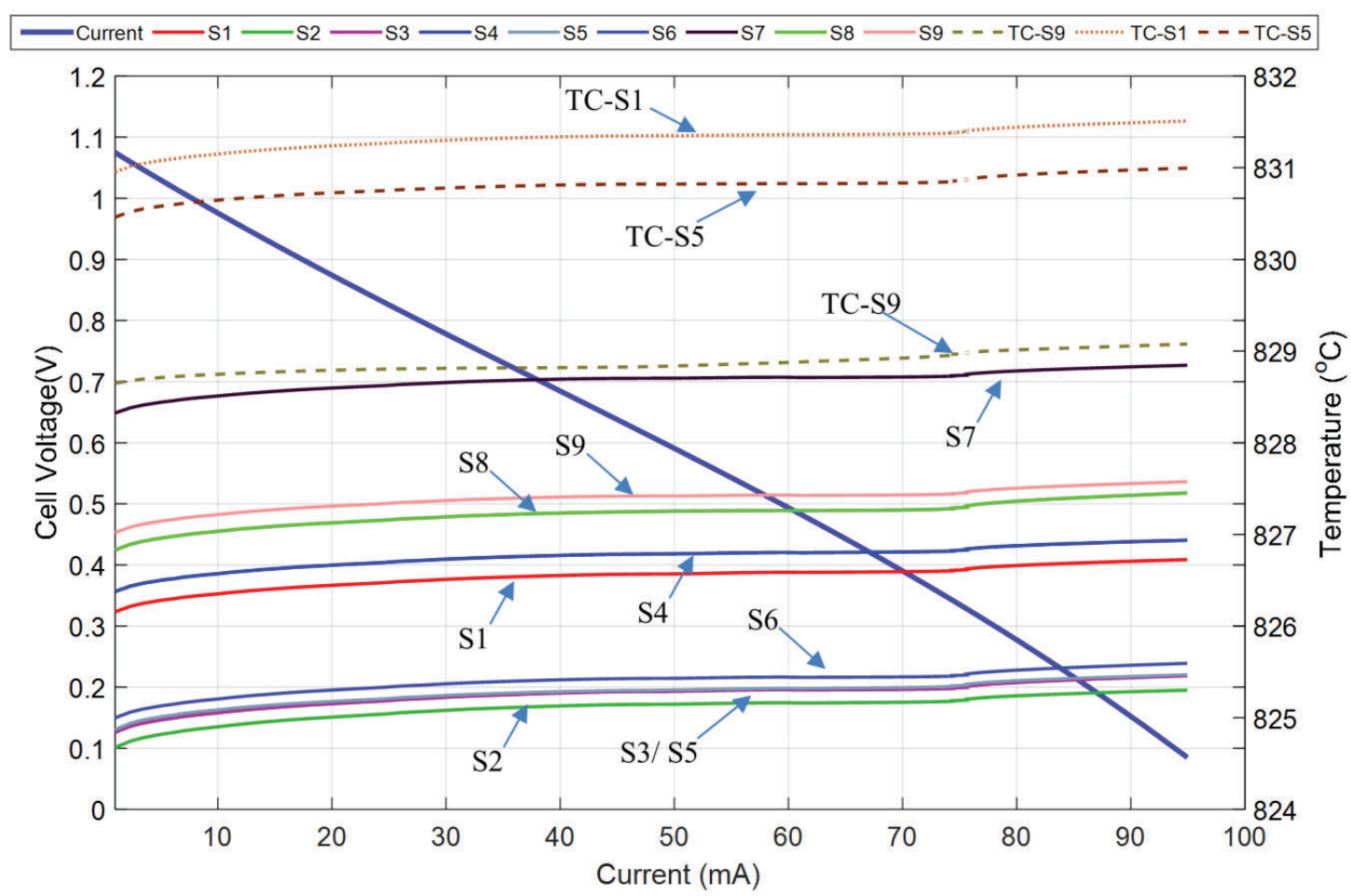

Fig. 7 The polarization curve of an operating cell (loading) with its temperature variations, due to the rate of drawn current, obtained from TCs and MCTA 
Table 2 Cell temperatures from MCTA at open circuit and $71 \mathrm{~mA}$ current

\begin{tabular}{|c|c|c|c|}
\hline \multirow{2}{*}{ Sensing point } & \multicolumn{2}{|c|}{ Local Temperature $\left({ }^{\circ} \mathrm{C}\right)$} & Temperature \\
\cline { 2 - 3 } & $\mathrm{I}=0 \mathrm{~mA}$ & $\mathrm{I}=71 \mathrm{~mA}$ & 0.54 \\
\hline S1 & 826.06 & 826.60 & 0.58 \\
\hline S2 & 824.60 & 825.18 & 0.58 \\
\hline S3 & 824.74 & 825.32 & 0.52 \\
\hline S4 & 826.30 & 826.82 & 0.63 \\
\hline S5 & 824.71 & 825.34 & 0.55 \\
\hline S6 & 824.91 & 825.46 & 0.48 \\
\hline S7 & 828.25 & 828.73 & 0.59 \\
\hline S8 & 826.69 & 827.28 & 0.51 \\
\hline S9 & 826.93 & 827.44 & 0.51 \\
\hline TC-S1 & 830.87 & 831.38 & 0.49 \\
\hline TC-S5 & 830.36 & 830.85 & 0.35 \\
\hline TC-S9 & 828.59 & 828.94 & \\
\hline
\end{tabular}

The cell continued to deliver low power and current densities throughout the experiments where the current density before concentration polarisation was as small as $0.005 \mathrm{~A} / \mathrm{cm}^{2}$ and the resulting power density was approximately $1.5 \mathrm{~mW} / \mathrm{cm}^{2}$. These values are much lower than the manufacturer's specifications where the cell can deliver current density of approximately $1.3 \mathrm{~A} /$ $\mathrm{cm}^{2}$. This low output is unlikely caused due to insufficient anode reduction, considering the process time, where 20 min reduction was sufficient with the same materials [29]. A more plausible explanation for the low power density is (a) excessively high lead resistance from long and thin wires (b) low active area from current collector coverage which influences TPB plus possibly (c) because the measurements were two probe, thus contact and lead resistance is not eliminated the improper gas distribution across the cell. In the test rig, the fuel entered perpendicularly to the cell from the centre region of it, approximately $2 \mathrm{~cm}$ below the anode surface. Thus, there is a possibility that only the area above the fuel pipe receives sufficient fuel 


\begin{tabular}{|c|c|c|c|c|}
\hline Sensing points & $\begin{array}{c}\text { Mean } \\
\text { difference }\end{array}$ & $\begin{array}{c}\text { Standard deviation } \\
\text { of the difference }\end{array}$ & $\begin{array}{c}\text { Thermocouple } \\
\text { error at } 800{ }^{\circ} \mathrm{C}\end{array}$ & Uncertainty \\
\hline & & & & \\
\hline S1 (and TC-S1) & $3.8970^{\circ} \mathrm{C}$ & $0.0304^{\circ} \mathrm{C}$ & $1.50^{\circ} \mathrm{C}$ & $0.0^{\circ} \mathrm{C}$ \\
\hline $\mathrm{S} 5$ (and TC-S5) & $4.2949^{\circ} \mathrm{C}$ & $0.0459^{\circ} \mathrm{C}$ & $1.72{ }^{\circ} \mathrm{C}$ & $0.0^{\circ} \mathrm{C}$ \\
\hline S9 (and TC-S9) & $-0.2892^{\circ} \mathrm{C}$ & $0.0785^{\circ} \mathrm{C}$ & $2.30^{\circ} \mathrm{C}$ & $2.8^{\circ} \mathrm{C}$ \\
\hline
\end{tabular}

Considering the accuracy of the commercial thermocouples and their uncertainty in calibration, it can be asserted that the grid's sensing points measured temperature as with similar fidelity to the commercial thermocouples in the tested conditions. The effect of load fluctuations on the cell temperature was investigated. A rise of the cell temperature with the increase of current was 
observed. Increasing the current approximately by $71 \mathrm{~mA}$ caused the cell temperature to increase by about $0.53{ }^{\circ} \mathrm{C}$. A larger current could not be drawn from the cell. It is reconfirmed that the increase of cell temperature causes a decrease to the OCV while increasing the operating cell voltage. With the improvement in experimental texture and structure feasibility of the MCTA, the method can be applicable for variety of technologies including fuel cell, and batteries for effective detection of temperature correlated information from the systems. It can also be considered as diagnostic tool for such high temperature energy devices to monitor temperature induced failure mechanism due to its sensitive detection capabilities. The obtained profile and correlation is elaborating the SOFCs state of performance and laying the groundwork via empirically measured interdependence of the temperature, flow rate and electrical loading is providing crucial data and basis for machine learning and failure diagnostic methods in real-time SOFC operation. Inputs from the temperature distribution of an operational SOFC are being used for training and deducing failure mechanisms through machine learning, research of which is being conducted at the author's group.

\section{CONCLUSIONS}

A thin film multi-channel thermocouple array (MCTA) having four sensing points was sputter deposited on the cathode of a commercial SOFC cell while grid structured thin wired- sensor with nine sensing points physically located on the cell surface by securing not electrical contact with the cell surface. MCTA requires only five thermoelements and six thermoelements to make independent temperature measurements from four and nine sensing points with $\mathrm{N}+1$ array and $3 \times 3$ grid architecture, respectively. Thus, it covers less surface area than a set of four thermocouples would cover with its eight thermoelements. By the carried out experimental process, the following conclusion can be drawn.

1. The cell-integrated MCTA monitored the presence of notably high temperature gradients across the cell itself under different flow configurations meanwhile, the commercial thermocouples placed less than $5 \mathrm{~mm}$ adjacency to the cathode were completely non- 
responsive to the temperature variations on the cell. This confirms that near-surface temperature sensing is not sufficient to sense cell temperature distribution of SOFCs.

2. Cell temperature measured by the thin film MCTA shows that cell cooling due to chilled gasses and fuel leakages can introduce significant temperature gradients across the cell, which may in turn potentially lead to cell failure in long term operation due to induction of high level thermal stresses which is undesirable.

3. Internal gas leakage is a major safety concern and it is not always feasible to detect them unless a system-wide inspection is carried out and such tasks are usually performed whilst the system is not in operation. In combination with the 3D view of temperature data collated by MCTA, the location and extent of such leaks can be made apparent. Furthermore, this approach can be extended to detecting the location of mechanical faults and cracks, as they would interrupt the signal gathered by MCTA across specific sensing points.

4. The MCTA enables this in-situ detection of gas leakage in correlation with the corresponding cell performance. This highlights the potential of the MCTA both as a diagnostic tool, which could enhance thermal analyses during abuse testing, identifying short-circuiting resistances via dynamic thermal events and as an effective method for thermal model validation. We can further envisage that such in-situ measurements, if incorporated in commercial cells, can drastically cut down on maintenance/shut-off periods and repair cycles, which will improve the commercial feasibility as well as the positive perception/impact into people's daily lives that is expected when these devices hit the mainstream.

The authors are confident to assert that the MCTA concept is applicable in either thin-film via sputtering or thin-wire based configurations via wire spot-welding, and that future applications can benefit from this flexibility in arrangement and packaging. The reversibly proportional correlation between the OCV and the cell temperature, as suggested by the Nernst equation could deserve further experimental investigation. 


\section{ACKNOWLEDGEMENT}

The authors appreciate partial financial support from EPSRC's the India-UK Collaborative Research Initiative in Fuel Cells project on "Modelling Accelerated Ageing and Degradation of Solid Oxide Fuel Cells" (EP/I037059/1), and also the EPSRC's UK-Korea Collaborative Research Activity in Fuel Cells project on "Novel diagnostic tools and techniques for monitoring and control of SOFC stacks" (EP/M02346X/1), and also Brain Pool Program through the National Research Foundation of Korea (NRF) funded by the Ministry of Science and ICT (2019H1D3A2A01101483). The name of MCTA was created and copyrighted by J.-S. Kim.

\section{REFERENCES}

[1] L. Mantelli, M. De Campo, M. L. Ferrari, and L. Magistri, "Fuel flexibility for a turbocharged SOFC system," Energy Procedia, vol. 158, pp. 1974-1979, 2019.

[2] A. B. Stambouli and E. Traversa, "Solid oxide fuel cells (SOFCs): A review of an environmentally clean and efficient source of energy," Renew. Sustain. Energy Rev., vol. 6, no. 5, pp. 433-455, 2002.

[3] E. Guk, V. Venkatesan, S. Babar, L. Jackson, and J. S. Kim, "Parameters and their impacts on the temperature distribution and thermal gradient of solid oxide fuel cell," Appl. Energy, vol. 241, no. February, pp. 164-173, 2019.

[4] E. Guk, J. S. Kim, M. Ranaweera, V. Venkatesan, and L. Jackson, "In-situ monitoring of temperature distribution in operating solid oxide fuel cell cathode using proprietary sensory techniques versus commercial thermocouples," Appl. Energy, vol. 230, no. May, pp. 551-562, 2018.

[5] E. Guk, M. Ranaweera, V. Venkatesan, and J.-S. Kim, "Performance and Durability of Thin Film Thermocouple Array on a Porous Electrode," Sensors, vol. 16, no. 9, p. 1329, Aug. 2016.

[6] E. Guk, V. Venkatesan, Y. Sayan, L. Jackson, and J. S. Kim, "Spring Based Connection of External Wires to a Thin Film Temperature Sensor Integrated Inside a Solid Oxide Fuel 
Cell," Sci. Rep., vol. 9, no. 1, pp. 1-11, 2019.

[7] E. Guk, "Real Time Temperature Distribution Monitoring of SOFC Cathode and Contributing Parameters," Loughborough University, 2018.

[8] M. Ranaweera and J.-S. Kim, "Cell integrated multi-junction thermocouple array for solid oxide fuel cell temperature sensing: N+1 architecture," J. Power Sources, vol. 315, pp. 7078, May 2016.

[9] M. Andersson, J. Yuan, and B. Sundén, "Review on modeling development for multiscale chemical reactions coupled transport phenomena in solid oxide fuel cells," Applied Energy. 2010.

[10] S. Chen, N. Lior, and W. Xiang, "Coal gasification integration with solid oxide fuel cell and chemical looping combustion for high-efficiency power generation with inherent $\mathrm{CO} 2$ capture," Appl. Energy, 2015.

[11] L. Barelli, G. Bidini, and A. Ottaviano, "Solid oxide fuel cell modelling: Electrochemical performance and thermal management during load-following operation," Energy, 2016.

[12] M. Bianco, J. P. Ouweltjes, and J. Van herle, "Degradation analysis of commercial interconnect materials for solid oxide fuel cells in stacks operated up to 18000 hours," Int. J. Hydrogen Energy, 2019.

[13] A. Buonomano, F. Calise, M. D. d'Accadia, A. Palombo, and M. Vicidomini, "Hybrid solid oxide fuel cells-gas turbine systems for combined heat and power: A review," Applied Energy. 2015.

[14] V. Zaccaria, D. Tucker, and A. Traverso, "Operating strategies to minimize degradation in fuel cell gas turbine hybrids," Appl. Energy, 2017.

[15] Z. Stoynov et al., "Differential analysis of SOFC current-voltage characteristics," Appl. Energy, 2018.

[16] J. E. A. Saunders and M. H. Davy, "In-situ studies of gas phase composition and anode surface temperature through a model DIR-SOFC steam-methane reformer at $973.15 \mathrm{~K}$," Int. J. Hydrogen Energy, vol. 38, no. 31, pp. 13762-13773, 2013.

[17] R. C. Maher, L. F. Cohen, P. Lohsoontorn, D. J. L. Brett, and N. P. Brandon, "Raman spectroscopy as a probe of temperature and oxidation state for gadolinium-doped ceria 
[18] N. Mahato, A. Banerjee, A. Gupta, S. Omar, and K. Balani, "Progress in material selection for solid oxide fuel cell technology: A review," Progress in Materials Science. 2015.

[19] O. Razbani, I. Wærnhus, and M. Assadi, "Experimental investigation of temperature distribution over a planar solid oxide fuel cell," Appl. Energy, vol. 105, pp. 155-160, May 2013.

[20] L. Yang, Y. Zhao, C. Feng, and H. Zhou, "The influence of size effect on sensitivity of Cu/CuNi thin-film thermocouple," Phys. Procedia, vol. 22, pp. 95-100, 2011.

[21] M. Cattani, M. C. Salvadori, A. R. Vaz, F. S. Teixeira, and I. G. Brown, "Thermoelectric power in very thin film thermocouples: Quantum size effects," J. Appl. Phys., vol. 100, no. 11, 2006.

[22] X. Zhang, H. Choi, A. Datta, and X. Li, "Design, fabrication and characterization of metal embedded thin film thermocouples with various film thicknesses and junction sizes," J. Micromechanics Microengineering, vol. 16, no. 5, pp. 900-905, May 2006.

[23] H. Liu, W. Sun, Q. Chen, and S. Xu, "Thin-film thermocouple array for time-resolved local temperature mapping," IEEE Electron Device Lett., vol. 32, no. 11, pp. 1606-1608, 2011.

[24] M. Ranaweera, E. Guk, I. Choi, and J. Kim, "Cathode temperature distribution of a solid oxide fuel cell measured via a thin film multi-junction thermocouple array," pp. 31-33.

[25] E. Guk, V. Venkatesan, Y. Sayan, L. Jackson, and J. S. Kim, "Spring Based Connection of External Wires to a Thin Film Temperature Sensor Integrated Inside a Solid Oxide Fuel Cell," Sci. Rep., 2019.

[26] E. Guk, M. Ranaweera, V. Venkatesan, and J.-S. Kim, "Performance and durability of thin film thermocouple array on a porous electrode," Sensors (Switzerland), vol. 16, no. 9, 2016.

[27] G. L. Wei, M. Liu, J. L. Luo, A. R. Sanger, and K. T. Chuang, "Influence of Gas Flow Rate on Performance of H[sub 2]S/Air Solid Oxide Fuel Cells with MoS[sub 2]-NiS-Ag Anode," J. Electrochem. Soc., vol. 150, no. 4, p. A463, 2003.

[28] J. Kupecki et al., "Numerical model of planar anode supported solid oxide fuel cell fed with fuel containing H2S operated in direct internal reforming mode (DIR-SOFC)," Appl. Energy, vol. 230, no. March, pp. 1573-1584, 2018. 
[29] C. Mallon and K. Kendall, "Sensitivity of nickel cermet anodes to reduction conditions," J. Power Sources, 2005.

[30] L. K. Chiang, H. C. Liu, Y. H. Shiu, C. H. Lee, and R. Y. Lee, "Thermo-electrochemical and thermal stress analysis for an anode-supported SOFC cell," Renew. Energy, vol. 33, no. 12, pp. 2580-2588, 2008. 